ORIGINAL ARTICLE

\title{
Mortality and cancer incidence among Lithuanian cement producing workers
}

\author{
G Smailyte, J Kurtinaitis, A Andersen
}

Occup Environ Med 2004;61:529-534. doi: 10.1136/oem.2003.009936

See end of article for authors' affiliations ......................

Correspondence to: Ms G Smailyte, Lithuanian Cancer Registry, Polocko 2. Vilnius, Lithuania, 2007; giedresm@one.lt

Accepted

28 November 2003

\begin{abstract}
Aims: To investigate mortality and cancer incidence of cement producing workers.
Methods: A total of 2498 cement workers who have been employed at Portland cement producing departments for at least one year from 1956 to 2000 were followed up from 1 January 1978 to 31 December 2000. The cohort contributed 43490 person-years to the study. Standardised incidence ratios (SIR) and standardised mortality ratios (SMR) were calculated as ratios between observed and expected numbers of cancers and deaths. The expected numbers were based on sex specific incidence and mortality rates for the total Lithuanian population.

Results: Significantly increased SMRs were found for all malignant neoplasms (SMR 1.3, 95\% Cl 1.0 to 1.5) and for lung cancer (SMR 1.4, 95\% Cl 1.0 to 1.9) among male cement workers. SIR for all cancer sites was 1.2 (95\% Cl 1.0 to 1.4). Excess risk was found for cancer of the lung (SIR 1.5, 95\% Cl 1.1 to 2.1). The SIR for urinary bladder cancer was also increased (SIR 1.8, 95\% Cl 0.9 to 3.5). The overall cancer incidence was not increased among females (SIR $0.8,95 \% \mathrm{Cl} 0.6$ to 1.1 ). With increasing cumulated exposure to cement dust, there were indications of an increasing risk of lung and stomach cancers among males.

Conclusions: This study supported the hypothesis that exposure to cement dust may increase the lung and bladder cancer risk. A dose related risk was found for stomach cancer, but no support was found for an increased risk of colorectal cancer.
\end{abstract}

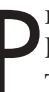
roduction of cement is a dusty industrial process and the health of the workers has been studied for many years. There is strong evidence for the association between dermal exposure to cement and the occurrence of allergic dermatitis, and contradictory evidence of any impairment of lung function arising from inhalation of cement dust. ${ }^{1-3}$

The possible carcinogenic effect of cement dust has been addressed in case-control and cohort studies. Census and register based studies have also found increased risk of lung and stomach cancer among cement and concrete workers. ${ }^{45}$ Laryngeal cancer has been associated with exposure to cement dust in a case-control study. ${ }^{\circ}$

An increased risk for stomach cancer among cement producing workers has been suggested, ${ }^{7}$ but the results are contradictory. ${ }^{8}{ }^{10}$ The interpretation of solitary epidemiological studies showing excess risk of cancer linked to occupational exposure is not without problems. ${ }^{11}$ It can be questioned whether the risk is due to dust exposure or lifestyle factors ${ }^{12}$ as several studies lack evidence of a dose related risk.

Jakobsson et al carried out studies at two Swedish cement factories and reported an increased risk of colorectal cancer, mainly due to increased risk of the right part of colon. ${ }^{10}$ However, in another study among Swedish concrete workers the authors found a reduced risk of cancer of the large intestine. ${ }^{13}$

A small study of masons handling cement showed an increased risk of lung cancer. ${ }^{14}$ The exposure information in the latter study was limited, and the authors suggested hexavalent chromium in the cement as a possible causal link. No cohort study has found any excess of lung cancer among cement manufacturers. ${ }^{79}{ }^{10}$ However, a study among concrete workers ${ }^{13}$ showed an increased lung cancer risk in line with the two census based studies. ${ }^{45}$ The authors concluded, however, that the risk could also be explained by smoking.
These intriguing findings create a need for more cohort studies among workers exposed to cement, and the aim of the present study was to investigate mortality and cancer incidence in a cohort of cement producing workers of both genders in the Lithuanian cement factory. Our main focus was towards the relation between exposure to cement dust and gastrointestinal and lung cancers.

\section{METHODS}

\section{Factory and production process}

In Lithuania, cement has only been manufactured in the Akmenes cementas factory. The plant was opened in 1952 in the town of Naujoji Akmene in the northwestern part of Lithuania. Only local raw materials were used in production. There were two cement producing facilities at the plant. The first one started to operate in 1952. Until 1970, 960 thousand tons were produced every year. From 1970 to 1974, when a new production line (second facility) was put into operation, the annual production level was 3.3 million tons. The factory has produced Portland cement only.

Limestone, clay, water, pyrites, gypsum, and sand were the main components of the cement. A wet process was used in clinker production in both facilities. Washed clay, water, pyrites, and crushed limestone were turned into a slurry in raw material mills. A $36 \%$ moisture of the raw material was obtained in slurry basins. Then the slurry went to rotary kilns, in which, at a temperature of $1450^{\circ} \mathrm{C}$, it was calcined to the artificial mineral clinker. The kilns were heated with oil during the whole production period. Clinker together with gypsum and other additives were ground in cement mills. With the help of compressed air it was transported from the mills to the silos for storage. Finally, cement was packed and transported from the plant. 


\section{Main messages}

- There was a significant excess risk of lung cancer in male cement workers both in the mortality and in the incidence data. The lung cancer risk was significantly increased in the two groups with the highest cumulated exposure to dust.

- There was an indication of a link between dust and the risk of stomach cancer, but no support was found for an increased risk of colorectal cancer.

\section{Exposure}

Exposure data by different departments exist from 1975 (table 1) as annual dust mass measurements (stationary measurements). The measurements were performed four times per year at different workplaces and the arithmetic means per year were presented. In the calculation of cumulative dose we used the annual mean mass measurements. The highest dust concentrations were found in the packing department. In the period 1975-2000, the concentration of cement dust in this department varied from 15.0 to $22.2 \mathrm{mg} / \mathrm{m}^{3}$. The annual average dust concentration in the calcining department in 1975 was $37.6 \mathrm{mg} / \mathrm{m}^{3}$, in later years less than $20.0 \mathrm{mg} / \mathrm{m}^{3}$ (facility II). In other departments the dust concentrations were lower. The exposure levels in the departments for crumbling and preparing of the raw material were less than $5 \mathrm{mg} / \mathrm{m}^{3}$, while other departments had between 5 and $10 \mathrm{mg} / \mathrm{m}^{3}$. The content of chromium(VI) in the cement and raw materials has never been analysed. Since the 1990s, and only for the European market, ferrous sulphate has been added into cement for reduction of chromium(VI) to chromium(III).

\section{The cohort}

Information on each worker was obtained from the factory records including name, date of birth, departments, and the beginning and ending dates of all employments, even for those who had been employed more than once. Our study group included workers who had been employed at the cement producing departments for a minimum of 12 months from 1956 to 2000. Those working in administration were not included. In 1963, departments for production of asbestos cement plates and pipes were opened. In our study group, 389 workers had been engaged in both cement and asbestos cement production.

The study population was followed up for cancer incidence, date of emigration, and date of death from the beginning of 1978 to the end of 2000. The study was confined to workers who were under observation from the beginning of the follow up period on 1 January 1978. The vital status of the cohort was traced to 31 December 2000.

Information on vital status, emigration, and date of death was obtained both from the local migration office and from the Bureau of Addresses of the Central Population Register. Members of the study group not identified from these two sources were traced through the Registry Department of the Lithuanian National History Archive where all deaths in the Lithuanian population are registered by date of death. Table 2 shows the vital status of the study population, where 2498 of 2662 cement workers $(93.8 \%)$ were included in the study group. Most of the workers lost to follow up were lost before 1978, the start of the present study.

The cancer cases in the cohort were identified in the Lithuanian Cancer Registry by linkage procedures using sex, name, and date of birth. In Lithuania, registration of cancer incidence is based on compulsory reporting of new cases from

\section{Policy implications}

- There is contradictory evidence in the scientific literature for the association between exposure to cement dust and cancer risk; further research is needed before a firm conclusion can be drawn.

all hospitals. The systematic information was available in a computerised database at the Cancer Registry from the year 1978. The cancer diagnoses were coded according to the WHO 9th Revision of International Classification of diseases (ICD-9).

Copies of the death certificates were obtained from the Archive Department of the Local Municipality and the Registry Department of the Lithuanian National History Archive and coded at the Cancer Registry.

For dose-response analyses individual cumulative exposure was used, calculated for each person-year of observation as the product of exposure intensity and duration summed for all employments. The $\chi^{2}$ test for trend was performed by assigning the arithmetic mean of cumulative total dust exposure to the exposure categories. ${ }^{15}$ The material was divided into four exposure categories based on an equal distribution of the number of person-years in each category. For the years 1954-74, we used dust measurements of the year 1975. All maintenance workers were excluded from the dose-response analysis because of unknown exposure (183 workers).

Standardised incidence ratios (SIR) and standardised mortality ratios (SMR) were calculated as ratios between observed and expected numbers of cancers and deaths, respectively. The expected numbers were based on sex specific incidence and mortality rates in five year age groups and five year observation periods for the total Lithuanian population. Follow up for each individual started after 12 months of total employment for those with first entry after 1 January 1978 and at 1 January 1978 if the worker reached 12 months of employment before that date. Workers who died or emigrated were followed until the time of these events, while all others were followed to the end of 2000. For 35 workers lost to follow up during the observation period, person-years were calculated up to the date of discharge from the factory. The cohort contributed 43490 person-years to the study (29 288 for males and 14202 for females).

Calculations of all SIRs and SMRs and 95\% confidence intervals (95\% CI) were performed with the program package STATA. ${ }^{16}$

\section{RESULTS}

The overall mortality among male cement workers was not increased (SMR 1.0, 95\% CI 0.9 to 1.1) (table 3); however, death from malignant neoplasms was increased in males (SMR 1.3, 95\% CI 1.0 to 1.5), mainly due to lung cancer mortality (SMR 1.4, 95\% CI 1.0 to 1.9). The work at the cement factory was very dusty, but no excess mortality for non-malignant respiratory diseases was observed (SMR 0.8, $95 \%$ CI 0.5 to 1.3 ). The overall mortality was not increased among female cement workers (observed 74 deaths, SMR 0.8 , 95\% CI 0.6 to 1.0$)$.

Among male cement workers, a total of 141 cases of cancer were observed against 115.3 expected (SIR 1.2, 95\% CI 1.0 to 1.4 , table 4 ). The number of lung cancer cases among male cement workers was significantly increased compared with expected numbers (SIR 1.5, 95\% CI 1.1 to 2.1). In addition, an increased SIR from cancer of the skin and urinary bladder was observed (SIR 1.4, 95\% CI 0.8 to 2.5 and SIR 1.8, 95\% CI 0.9 to 3.5 , respectively). The SIR for rectal cancer was also 


\begin{tabular}{|c|c|c|c|c|c|}
\hline & \multicolumn{5}{|c|}{ Total dust, $\mathrm{mg} / \mathrm{m}^{3}$} \\
\hline & $1975-79$ & $1980-84$ & $1985-89$ & 1990-94 & $1995-2000$ \\
\hline \multicolumn{6}{|l|}{ Raw material } \\
\hline Preparing & 2.9 & 3.5 & 3.2 & 3.2 & 3.1 \\
\hline Crumbling and sorting & 2.9 & 3.6 & 3.8 & 3.2 & 9.1 \\
\hline \multicolumn{6}{|l|}{ Facility I } \\
\hline Calcining & 7.9 & 8.2 & 8.9 & 7.7 & \\
\hline Milling & 5.1 & 6.0 & 6.3 & 7.0 & \\
\hline \multicolumn{6}{|l|}{ Facility II } \\
\hline Calcining & 19.2 & 11.1 & 8.2 & 12.4 & 17.1 \\
\hline Milling & 9.1 & 9.1 & 7.9 & 8.2 & 11.2 \\
\hline Transport and packing & 19.1 & 16.6 & 12.8 & 18.5 & 15.0 \\
\hline Repair and machine & 3.7 & 3.8 & 3.4 & 2.8 & 3.7 \\
\hline
\end{tabular}

increased (SIR 1.4, 95\% CI 0.6 to 2.8), whereas the number of cases of stomach cancer was lower than expected (SIR 0.7, 95\% CI 0.2 to 2.1 ).

For female workers the overall incidence of cancer was not increased (SIR 0.8, 95\% CI 0.6 to 1.1). The observed numbers of cancers at specific sites however were based on few cases only.

One case of mesothelioma was found among males versus the expected 0.3 . The mesothelioma occurred in a 42 year old worker with less than two years of exposure at the department of raw material preparation, five years after his first employment. He had no known asbestos exposure at the factory.

A total of 389 cement producing workers had also been at any time engaged in asbestos cement production at the same enterprise. When this subgroup was excluded the results for lung cancer were as follows: in males, 34 observed cases, giving an SIR of 1.4 (95\% CI 1.0 to 2.0); and in females, three observed cases, giving an SIR of 2.0 (95\% CI 0.7 to 6.3 ).

Table 5 presents the SIRs according to the number of years since first employment and duration of employment in male workers. As there were so few cancer cases among females, we do not present detailed data for this group. For colorectal cancer the relative risk increased with increasing time since first employment. No such increase was observed for stomach and lung cancers. However, increasing risk with increasing duration of employment was observed for lung cancer, especially in the group with 25 or more years since first exposure. Among those with 15 years and more of employment we saw an increased SIR for skin cancer (SIR 2.2, 95\% CI 1.0 to 4.8 ), based on six cases.

Table 6 shows cancer risk by cumulated dose in cement workers. With increasing cumulated dose of dust as an index of exposure, the table shows an increasing trend for stomach cancer $(p<0.05)$, while the lung cancer risk was significantly increased in the two groups with the highest cumulated exposure (test for trend, $\mathrm{p}=0.3$ ).

\section{DISCUSSION}

The present study includes 43490 person-years from the follow up period 1978-2000, for both genders combined. The study showed an excess mortality risk from malignant neoplasms, and a borderline significant increased risk of death from lung cancer. The incidence data also revealed an excess risk of lung and bladder cancers. The lung cancer risk increased with increasing cumulative exposure to dust, but for bladder cancer the study showed no such trend. There was also an indication of a link between dust and the risk of stomach cancer.

There is only one cement factory in Lithuania, therefore all cement producing workers in the country are included in this study, both males and females. Loss to follow up was a problem, especially before 1978, because few sources with information on people who had emigrated existed. In this study $4.4 \%$ of the workers who left the factory before 1978 were impossible to trace, while loss to follow up after 1978 was only $1.3 \%$ of the total cohort. In the same area where the cement factory is located there is also an asbestos cement factory, and $16 \%$ of the workers had worked in both factories. Results from the present study showed no higher risk of lung cancer among previous asbestos cement workers than among cement workers only. ${ }^{17}$ We therefore also included these workers in the present study.

The estimation of cumulated dose of dust exposure has probably led to some misclassification. The exposure intensity was based on stationary measurements at department level, and all workers within a department were given the same exposure level. Differences between job tasks were therefore not reflected in the exposure estimates. The misclassification resulting from these problems was non-differential and would tend to mask the true dose-response relations, or flatten the dose-response curve. ${ }^{18}$

In our study, a significant excess risk of lung cancer in males was found both in the mortality and in the incidence data (tables 3 and 4). Significant excess was also observed in

Table 2 Vital status of the cement workers employed in cement producing departments between 1956 and 2000

\begin{tabular}{lrrrrrr}
\hline Vital status & Males & \multicolumn{1}{l}{$\%$} & \multicolumn{1}{l}{ Females } & \multicolumn{1}{l}{$\%$} & \multicolumn{1}{c}{ Total } & \multicolumn{1}{l}{$\%$} \\
\hline Total & 1841 & 100.0 & 821 & 100.0 & 2662 & 100.0 \\
Alive 31 December 2000 & 1304 & 70.8 & 676 & 82.3 & 1980 & 74.4 \\
Dead before 1978 & 44 & 2.4 & 4 & 0.5 & 48 & 1.8 \\
Dead 1978 or later & 376 & 20.4 & 74 & 9.0 & 450 & 16.9 \\
Emigrated 1978 or later & 23 & 1.2 & 10 & 1.2 & 33 & 1.2 \\
Lost to follow up before 1978 & 70 & 3.8 & 46 & 5.6 & 116 & 4.4 \\
Lost to follow up 1978 or later & 24 & 1.3 & 11 & 1.3 & 35 & 1.3 \\
Included in the study & 1727 & 93.8 & 771 & 93.9 & 2498 & 93.8 \\
\hline
\end{tabular}


Table 3 Observed (Obs) number of deaths and standardised mortality ratios (SMR) among cement workers during the follow up period 1978-2000

\begin{tabular}{|c|c|c|c|c|c|c|c|}
\hline \multirow[b]{2}{*}{ Cause of death } & \multirow[b]{2}{*}{ ICD-9 code } & \multicolumn{3}{|c|}{ Males $(n=1727)$} & \multicolumn{3}{|c|}{ Females $(n=771)$} \\
\hline & & Obs & SMR & $95 \% \mathrm{Cl}$ & Obs & SMR & $95 \% \mathrm{Cl}$ \\
\hline All causes & 001-999 & 376 & 1.0 & 0.9 to 1.1 & 74 & 0.8 & 0.6 to 1.0 \\
\hline Infectious diseases & $001-139$ & 2 & 0.2 & 0.1 to 1.0 & - & - & - \\
\hline Malignant neoplasms & $140-208$ & 102 & 1.3 & 1.0 to 1.5 & 19 & 0.7 & 0.4 to 1.1 \\
\hline Stomach & 151 & 9 & 0.7 & 0.4 to 1.4 & 3 & 1.0 & 0.3 to 3.1 \\
\hline Colon and rectum & 153,154 & 7 & 1.1 & 0.5 to 2.3 & 1 & 0.4 & 0.1 to 2.6 \\
\hline Lung & 162 & 36 & 1.4 & 1.0 to 1.9 & 2 & 1.4 & 0.3 to 5.5 \\
\hline Diseases of circulatory system & $390-459$ & 160 & 1.1 & 0.9 to 1.2 & 38 & 0.9 & 0.6 to 1.2 \\
\hline Diseases of respiratory system & $460-519$ & 16 & 0.8 & 0.5 to 1.3 & 3 & 1.0 & 0.3 to 3.0 \\
\hline Diseases of digestive system & $520-579$ & 12 & 1.0 & 0.6 to 1.7 & 1 & 0.3 & 0.1 to 2.0 \\
\hline Diseases of genitourinary system & $580-629$ & 4 & 0.9 & 0.3 to 2.4 & 3 & 1.8 & 0.6 to 5.6 \\
\hline Accidents and violence & $800-999$ & 66 & 0.7 & 0.5 to 0.9 & 6 & 0.6 & 0.3 to 1.3 \\
\hline Other causes of deaths & & $14^{*}$ & 0.7 & 0.4 to 1.2 & $4^{*}$ & 0.7 & 0.3 to 1.8 \\
\hline
\end{tabular}

the group with the longest period since first exposure and among those in the two highest cumulative dust exposure groups. In the groups with lowest level of exposure no excess risk of lung cancer was observed. An increased risk of lung cancer has also been reported in the Icelandic study among masons. ${ }^{14}$ Portland cement contains hexavalent chromium, which is an established cause of lung cancer. ${ }^{19}$ In the Icelandic study hexavalent chromium in cement dust was regarded as the most probable carcinogenic agent. The concentration of chromate in cement is low $(2-10 \mathrm{mg} / \mathrm{kg}) .{ }^{9}{ }^{14}$ Vestbo and colleagues ${ }^{9}$ also observed the highest risk in the group with the longest duration of exposure, but when they included smoking habits in their analysis the relative risk was reduced to 1.0. In a Swedish study, where the concentration of chromium in finished cement was up to $40 \mathrm{mg} / \mathrm{kg}$, no excess risk of lung cancer was reported. ${ }^{10}$

In all published studies from cement producing and user industries no direct data on smoking were available and only surrogates were used. In Lithuania, the smoking prevalence in males was $43 \%$ in 1994 and $51 \%$ in $2000 .{ }^{20}$ Unfortunately, we had no individual smoking data for the workers. We used the incidence rates for the whole population as reference. Blue collar workers in Lithuania smoke more than white collar workers. If we had selected blue collar workers as reference group for calculation of expected numbers, our results would have been closer to unity.

Our study also showed an overall increased risk of bladder cancer by year since first employment and by duration of employment, but no increased trend with increasing cumulated dose of dust exposure. Some cement factories have used coal in the calcining department that could cause a problem with polycyclic aromatic hydrocarbons as with bladder cancer, but the Lithuanian factory used only oil for such heating. The observed excess of bladder cancer does suggest that smoking could have been a confounder in our study. However, we found the dose related risk for lung cancer to be suggestive of a risk linked to dust exposure, but risk in these groups may also be due to misclassification of exposures. ${ }^{18}$

Work in a dusty environment has also been linked to stomach cancer in some studies. ${ }^{21}$ We found a significant dose related risk for stomach cancer among cement workers; our findings are in accordance with the study by McDowall. ${ }^{7}$ Two other studies of cement workers did not find an association between cement exposure and stomach cancer. ${ }^{8} 10$ The excess risk found among Swedish concrete workers was explained by a cohort effect rather than an occupational disease. ${ }^{13}$ The result is therefore difficult to interpret because it is well known that lifestyle factors are also of importance for this cancer. ${ }^{12}$

Table 4 Observed (Obs) number of new cancer cases and standardised incidence ratios (SIR) among the cement workers during the follow up period 1978-2000

\begin{tabular}{|c|c|c|c|c|c|c|c|}
\hline \multirow[b]{2}{*}{ Cancer site } & \multirow[b]{2}{*}{ ICD-9 code } & \multicolumn{3}{|c|}{ Males $(n=1727)$} & \multicolumn{3}{|c|}{ Females $(n=771)$} \\
\hline & & Obs & SIR & $95 \% \mathrm{Cl}$ & Obs & SIR & $95 \% \mathrm{Cl}$ \\
\hline All malignant neoplasms & $140-208$ & 141 & 1.2 & 1.0 to 1.4 & 41 & 0.8 & 0.6 to 1.1 \\
\hline Lip, mouth, and pharynx & $140-149$ & 8 & 1.3 & 0.6 to 2.5 & 0 & - & - \\
\hline Stomach & 151 & 11 & 0.7 & 0.4 to 1.3 & 3 & 0.8 & 0.3 to 2.5 \\
\hline Colon & 153 & 3 & 0.7 & 0.2 to 2.1 & 2 & 0.9 & 0.2 to 3.5 \\
\hline Rectum & 154 & 7 & 1.4 & 0.6 to 2.8 & 2 & 0.9 & 0.2 to 3.7 \\
\hline Pancreas & 157 & 4 & 0.9 & 0.3 to 2.4 & 0 & - & - \\
\hline Larynx & 161 & 5 & 1.0 & 0.4 to 2.4 & 0 & - & - \\
\hline Lung & 162 & 44 & 1.5 & 1.1 to 2.1 & 3 & 1.7 & 0.6 to 5.4 \\
\hline Melanoma & 172 & 2 & 1.9 & 0.5 to 7.9 & 0 & - & - \\
\hline Skin & 173 & 12 & 1.4 & 0.8 to 2.5 & 6 & 1.0 & 0.5 to 2.3 \\
\hline Breast & 174,175 & 0 & - & - & 7 & 0.6 & 0.3 to 1.3 \\
\hline Female genital organs & $179-184$ & - & - & - & 11 & 0.8 & 0.5 to 1.5 \\
\hline Prostate & 185 & 9 & 1.2 & 0.6 to 2.2 & - & - & - \\
\hline Urinary bladder & 188 & 8 & 1.8 & 0.9 to 3.5 & 1 & 1.9 & 0.3 to 13.4 \\
\hline Kidney & 189 & 5 & 1.0 & 0.4 to 2.4 & 2 & 1.2 & 0.3 to 4.8 \\
\hline Haematopoietic system & $200-208$ & 8 & 1.2 & 0.6 to 2.4 & 2 & 0.7 & 0.2 to 2.9 \\
\hline Other sites of cancer & & 15 & 1.1 & 0.7 to 1.9 & 2 & 0.4 & 0.1 to 1.7 \\
\hline
\end{tabular}




\begin{tabular}{|c|c|c|c|c|c|c|c|c|c|c|c|}
\hline \multirow[b]{3}{*}{ Cancer site } & \multirow[b]{3}{*}{ ICD-9 code } & \multirow{3}{*}{$\begin{array}{l}\text { Years since first } \\
\text { employment, } y\end{array}$} & \multicolumn{9}{|c|}{ Duration of employment, $y$} \\
\hline & & & \multicolumn{2}{|l|}{$1-2$} & \multicolumn{2}{|c|}{$3-14$} & \multicolumn{2}{|l|}{$>15$} & \multicolumn{3}{|l|}{ Total } \\
\hline & & & Obs & SIR & Obs & SIR & Obs & SIR & Obs & SIR & $95 \% \mathrm{Cl}$ \\
\hline \multirow[t]{4}{*}{ All malignant neoplasms } & $140-208$ & $<15$ & 5 & 1.0 & 28 & 1.6 & 2 & 0.3 & 35 & 1.2 & 0.9 to 1.7 \\
\hline & & $15-24$ & 6 & 1.1 & 21 & 1.0 & 20 & 1.5 & 47 & 1.2 & 0.9 to 1.7 \\
\hline & & $>25$ & 3 & 0.6 & 28 & 1.2 & 28 & 1.5 & 59 & 1.2 & 1.0 to 1.6 \\
\hline & & Total & 14 & 0.9 & 77 & 1.3 & 50 & 1.3 & 141 & 1.2 & 1.0 to 1.4 \\
\hline \multirow[t]{4}{*}{ Stomach } & 151 & $<15$ & 0 & - & 3 & 1.2 & 0 & - & 3 & 0.8 & 0.2 to 2.4 \\
\hline & & $15-24$ & 0 & - & 2 & 0.7 & 2 & 1.1 & 4 & 0.7 & 0.3 to 1.9 \\
\hline & & $>25$ & 0 & - & 2 & 0.8 & 2 & 1.0 & 4 & 0.8 & 0.2 to 1.8 \\
\hline & & Total & 0 & - & 7 & 0.9 & 4 & 0.9 & 11 & 0.7 & 0.4 to 1.3 \\
\hline \multirow[t]{4}{*}{ Colon and rectum } & 153,154 & $<15$ & 0 & - & 1 & 0.7 & 0 & & 1 & 0.5 & 0.1 to 3.3 \\
\hline & & $15-24$ & 0 & - & 1 & 0.6 & 2 & 1.9 & 3 & 0.9 & 0.3 to 2.9 \\
\hline & & $>25$ & 1 & 2.1 & 2 & 1.0 & 3 & 1.7 & 6 & 1.4 & 0.6 to 3.1 \\
\hline & & Total & 1 & 0.8 & 4 & 0.8 & 5 & 1.6 & 10 & 1.1 & 0.6 to 2.0 \\
\hline \multirow[t]{4}{*}{ Lung } & 162 & $<15$ & 1 & 0.9 & 9 & 2.1 & 1 & 0.7 & 11 & 1.7 & 0.9 to 3.0 \\
\hline & & $15-24$ & 3 & 2.2 & 4 & 0.8 & 5 & 1.4 & 12 & 1.2 & 0.7 to 2.1 \\
\hline & & $>25$ & 1 & 0.7 & 10 & 1.7 & 10 & 2.0 & 21 & 1.7 & 1.1 to 3.8 \\
\hline & & Total & 5 & 1.3 & 23 & 1.5 & 16 & 1.6 & 44 & 1.5 & 1.1 to 2.1 \\
\hline \multirow[t]{4}{*}{ Skin } & 173 & $<15$ & 1 & 2.8 & 2 & 1.6 & 0 & - & 3 & 1.5 & 0.5 to 4.6 \\
\hline & & $15-24$ & 0 & - & 2 & 1.3 & 2 & 2.2 & 4 & 1.4 & 0.5 to 3.8 \\
\hline & & $>25$ & 0 & - & 1 & 0.6 & 4 & 2.8 & 5 & 1.4 & 0.6 to 3.3 \\
\hline & & Total & 1 & 0.9 & 5 & 1.1 & 6 & 2.2 & 12 & 1.4 & 0.8 to 2.5 \\
\hline \multirow[t]{4}{*}{ Urinary bladder } & 188 & $<15$ & 0 & - & 1 & 1.7 & 0 & - & 1 & 1.1 & 0.2 to 7.5 \\
\hline & & $15-24$ & 0 & - & 1 & 1.2 & 2 & 4.2 & 3 & 2.0 & 0.6 to 6.0 \\
\hline & & $>25$ & 0 & - & 2 & 1.9 & 2 & 2.4 & 4 & 1.9 & 0.7 to 5.0 \\
\hline & & Total & 0 & - & 4 & 1.6 & 4 & 2.7 & 8 & 1.8 & 0.9 to 3.5 \\
\hline
\end{tabular}

The low risk of cancer in the large intestine found in the present study is not in accordance with results from Jakobsson and colleagues. ${ }^{10}$ However, our study showed an increased number of rectal cancers. In addition, there was some evidence of a slightly increased risk from rectal cancer in this industry as pointed out by McDowall. ${ }^{7}$ There were only five colon cancers in our study, three of which were located on the right side. For colon cancer we found the highest risk in the group with the longest period since first exposure, but no increased risk with cumulated dust exposure.

\begin{tabular}{|c|c|c|c|c|c|c|}
\hline \multirow[b]{2}{*}{ Cancer site } & \multirow[b]{2}{*}{ ICD-9 code } & \multirow[b]{2}{*}{ Exposure, $\mathrm{mg} / \mathrm{m}^{3}$} & \multicolumn{3}{|c|}{$n=1582$} & \multirow[b]{2}{*}{ Test for trend } \\
\hline & & & Obs & SIR & $95 \% \mathrm{Cl}$ & \\
\hline \multirow[t]{5}{*}{ All malignant neoplasms } & $140-208$ & $<20.6$ & 20 & 1.1 & 0.7 to 1.7 & \\
\hline & & $20.6-55.3$ & 28 & 1.2 & 0.8 to 1.7 & \\
\hline & & $55.4-130.2$ & 40 & 1.4 & 1.0 to 1.9 & \\
\hline & & $>130.2$ & 43 & 1.3 & 1.0 to 1.8 & \\
\hline & & Total & 131 & 1.3 & 1.1 to 1.5 & $p=0.4$ \\
\hline \multirow[t]{5}{*}{ Stomach } & 151 & $<20.6$ & 0 & - & - & \\
\hline & & $20.6-55.3$ & 1 & 0.3 & 0.04 to 2.2 & \\
\hline & & $55.4-130.2$ & 4 & 1.1 & 0.4 to 2.8 & \\
\hline & & $>130.2$ & 6 & 1.5 & 0.6 to 3.0 & \\
\hline & & Total & 11 & 0.9 & 0.4 to 1.4 & $p<0.05$ \\
\hline \multirow[t]{5}{*}{ Colon and rectum } & 153,154 & $<20.6$ & 1 & 0.7 & 0.1 to 4.6 & \\
\hline & & $20.6-55.3$ & 2 & 1.0 & 0.3 to 4.0 & \\
\hline & & $55.4-130.2$ & 3 & 1.2 & 0.4 to 3.8 & \\
\hline & & $>130.2$ & 4 & 1.4 & 0.5 to 3.8 & \\
\hline & & Total & 10 & 1.1 & 0.6 to 2.1 & $p=0.5$ \\
\hline \multirow{5}{*}{ Lung } & 162 & $<20.6$ & 6 & 1.3 & 0.6 to 3.0 & \\
\hline & & $20.6-55.3$ & 5 & 0.8 & 0.4 to 2.0 & \\
\hline & & $55.4-130.2$ & 14 & 2.0 & 1.2 to 3.4 & \\
\hline & & $>130.2$ & 15 & 1.8 & 1.1 to 3.0 & \\
\hline & & Total & 40 & 1.6 & 1.2 to 2.1 & $p=0.3$ \\
\hline \multirow[t]{5}{*}{ Skin } & 173 & $<20.6$ & 1 & 0.7 & 0.1 to 5.2 & \\
\hline & & $20.6-55.3$ & 4 & 2.3 & 0.9 to 6.1 & \\
\hline & & $55.4-130.2$ & 1 & 0.5 & 0.1 to 3.4 & \\
\hline & & $>130.2$ & 6 & 2.5 & 1.1 to 5.4 & \\
\hline & & Total & 12 & 1.6 & 0.9 to 2.8 & $p=0.4$ \\
\hline \multirow[t]{5}{*}{ Urinary bladder } & 188 & $<20.6$ & 1 & 1.4 & 0.2 to 10.2 & \\
\hline & & $20.6-55.3$ & 3 & 3.2 & 1.0 to 9.8 & \\
\hline & & $55.4-130.2$ & 1 & 0.8 & 0.1 to 6.0 & \\
\hline & & $>130.2$ & 2 & 1.5 & 0.4 to 6.0 & \\
\hline & & Total & 7 & 1.7 & 0.8 to 3.5 & $p=0.7$ \\
\hline
\end{tabular}


We also found an excess risk of skin cancer in our study. As there is strong evidence of an association between cement exposure and occurrence of allergic dermatitis we investigated the subsite for all 18 skin cancers, but no cases were identified on the hands.

\section{Conclusions}

This study supported the hypothesis that exposure to cement dust may increase the risk of lung and bladder cancer. A dose related risk was found for stomach cancer. No support was found for an increased risk of colorectal cancer; however more studies are necessary before a final conclusion can be drawn.

\section{ACKNOWLEDGEMENTS}

We are grateful to the administration of factory Akmenes cementas for permission to access the data, the staff of Akmene migration office for all practical help with identification of the study subjects, and to Jan Ivar Martinsen, Norwegian Cancer Registry for calculation of cumulative exposures.

\section{Authors' affiliations}

G Smailyte, J Kurtinaitis, Lithuanian Cancer Registry, Oncology Institute of Vilnius University, Vilnius, Lithuania

A Andersen, The Cancer Registry of Norway

\section{REFERENCES}

1 Bazas T. Effects of occupational exposure to dust on the respiratory system of cement workers. J Soc Occup Med 1980;30:31-6.

2 McDowall M. Cement workers and cancer: epidemiology at work? $\mathrm{Br} J$ Ind Med 1986;43:505-6.

3 Kjuus H, Lenvik K, Kjærheim K, et al. Epidemiological assessment of the occurrence of allergic dermatitis in workers in the construction industry related to the content of $\mathrm{Cr}(\mathrm{VI})$ in cement, STAMI-rapport no. 2. Oslo: National Institute of Occupational Health, 2003

4 Andersen A, Barlow L, Engeland A, et al. Work-related cancer in the Nordic countries. Scand J Work Environ Health 1999;25(suppl 2):1-116.

5 Pukkala E. Cancer risk by social class and occupation. A survey of 109000 cancer cases among Finns of working age. Contributions to epidemiology and biostatistics. Basel: Karger, 1995.

6 Olsen J, Sabroe S. Occupational causes of laryngeal cancer. J Epidemiol Community Health 1984;38:117-21.

7 McDowall ME. A mortality study of cement workers. $\mathrm{Br} J$ Ind Med 1984;41:179-82.

8 Amandus HE. Mortality from stomach cancer in United States cement plant and quarry workers, 1950-80. Br J Ind Med 1986;43:526-8.

9 Vestbo J, Knudsen KM, Raffn E, et al. Exposure to cement dust at a Portland cement factory and the risk of cancer. BrJ Ind Med 1991;48:803-7.

10 Jakobsson K, Horstmann V, Welinder H. Mortality and cancer morbidity among cement workers. Br J Ind Med 1993;50:264-72.

11 Doll R. Occupational cancer: a hazard for epidemiologist. Int J Epidemiol 1985:14:22-31.

12 Stukonis M, Doll R. Gastric cancer in man and physical activity at work. Int J Cancer 1969;4:248-54.

13 Knutsson A, Damber L, Järvholm B. Cancer in concrete workers: results of a cohort study of 33668 workers. Occup Environ Med 2000:57:264-7.

14 Rafnsson V, Gunnarsdottir H, Kiilunen M. Risk of lung cancer among masons in Iceland. Occup Environ Med 1997;54:184-8.

15 Breslow NE, Day NE. Statistical methods in cancer research, Vol. II: The design and analysis of cohort studies. IARC Scientific Publication No. 82 Lyon: IARC, 1987.

16 StataCorp. Stata statistical software: release 7.0. College Station, TX: Stata Corporation, 2001.

17 Smailyte G, Kurtinaitis J, Andersen A. Mortality and morbidity of cancer among workers in Lithuanian asbestos cement producing factories. Scand J Work Environ Health. In press.

18 Stayner L, Steenland K, Dosemeci $M$, et al. Attenuation of exposure-response curves in occupational cohort studies at high exposure levels. Scand I Work Environ Health 2003;29:317-24.

19 IARC. Chromium, nickel and welding, IARC monographs on the evaluation of carcinogenic risk of chemicals to humans. Vol. 49. Lyon: IARC, 1990.

20 http://cisid.who.dk/tobacco.

21 Siemiatycki J, Richardson L, Gérin M, et al. Associations between several sites of cancer and nine organic dusts: results from an hypothesis-generating casecontrol study in Montreal, 1979-1983. Am J Epidemiol 1986;123:235-49. 